\title{
Recent development of hydrothermal diamond-anvil cell and its applications in the study of fluid and melt inclusions
}

\author{
I-MING CHOU ${ }^{1}$, JIANKANG LI $^{2}$ AND WILLIAM A. \\ BASSETT $^{3}$ \\ ${ }^{1}$ Institute of Deep-sea Science and Engineering, Chinese \\ Academy of Sciences, No. 28 Luhuitou Rd., Sanya, \\ Hainan Province 572000, China (imchou@idsse.ac.cn) \\ ${ }^{2}$ MNR Key Laboratory of Metallogeny and Mineral \\ Assessment, Institute of Mineral Resources, Chinese \\ Academy of Geological Sciences, Beijing 100037, China \\ (Li9968@126.com) \\ ${ }^{3}$ Department of Earth and Atmospheric Sciences, Cornell \\ University, Ithaca, New York 14853, USA \\ (wab7@cornell.edu)
}

A new type of hydrothermal diamond-anvil cell (HDAC) was designed with smaller dimension than the old types and also with a freezing system. The new design greatly shortened the horizontal size of HDAC and provided more open space and short distance to analyse and observe the sample chamber when side access is used. The freezing system was designed to cool the sample chamber to $-170{ }^{\circ} \mathrm{C}$ with precision of \pm 0.2 ${ }^{\circ} \mathrm{C}$, and the cooling rate was controlled to be as low as 0.15 ${ }^{\circ} \mathrm{C} / \mathrm{min}$. These improvements extend the HDAC applications, especially in low temperature conditions. For example, the determinations of (1) bulk $\mathrm{H}_{2} \mathrm{O}$ density [1] and (2) the salinity of $\mathrm{NaCl}-\mathrm{H}_{2} \mathrm{O}$ loaded in the HDAC sample chamber by measuring ice melting temperature [2].

All types of HDAC have been widely used for the studies of mineral solubilities, phase relations, and speciation of aqueous fluids [3]. In addition, HDAC has been used to provide external pressures during heating of fluid/melt inclusions, with or without daughter minerals, to prevent their expansions and/or decrepitations before achieving total homogenization [4, 5, 6]. In situ observations and characterizations of total homogenization of these inclusions have provided essential information for establishing formation models of the host minerals and related geological processes $[4,5,6]$.

[1] Haselton et al. (1995) Am. Mineral., 80, 1302-1306. [2] Bodnar \& Vityk (1994) in Fluid Inclusions in Miner., Methods and Appl., 117-130. [3] Schmidt \& Chou (2012) EMU Notes in Mineral., 12, 248-278. [4] Schmidt et al. (1998) Am. Mineral., 83, 995-1007. [5] Li \& Chou (2017) J. . Geofluids, 2017, 9252913. [6] Li et al. (2017) J. Asian Earth Sci., 137, 180-193. 